\title{
Determination of Serogroup and Lytic Activities of Bacteriophages Isolated from Phage Plaques in Staphylococcus aureus Cultures Identified from Sheep Milk with Mastitis
}

Sevil Erdenliğ Gürbilek ${ }^{1}$, Neval Berrin Arserim², Osman Yaşar Tel ${ }^{1}$,

Zeynep Tugçe Sertkaya ${ }^{3}$, Oktay Keskin ${ }^{1}$

10.18805/IJAR.BF-1443

\begin{abstract}
Backgorund: Bacteriophages are closely related to the evolution and virulence of some important bacterial pathogens. Due to their highly significant roles in pathogenesis and virulence, $S$. aureus bacteriophages are frequently studied. Bacteriophages are grouped into two main categories depending on their life cycles. There are highly consistently lytic phages (virulent) and temperate phages. This study aimed to isolate bacteriophages and determine their phage serogroups from phage plaques in $S$. aureus cultures in order to show if they are lytic or lysogenic, the latter plays a major role in horizontal gene transfer.

Methods: A total of $234 \mathrm{~S}$. aureus isolates were recovered from milk samples from cases with gangrenous mastitis in sheep. Staphylococcal phages are determined based on the type and serogroup by PCR using specific primers.

Result: Our study allowed us to determine serogroups of the isolated bacteriophages. Two phage stock samples included only one serogroup while the others included more than one phage serotypes and needed further purification $F a, L$ and $D$ serogroups were not determined in the study. Present work revealed that all the isolated phages were temperate phages, which play a highly significant role in horizontal gene transfer.
\end{abstract}

Key words: Bacteriophages, Sheep, Staphyloccocus aureus.

\section{INTRODUCTION}

Mastitis is an inflammation of the mammary gland which causes severe economic loss in milk producing animals. Mastitis can occur due to specific microorganisms, mainly Staphylococcus aureus, coagulase-negative Staphylococci, streptococci, Escherichia coli, Mycoplasma agalactiae and Truperella pyogenes, etc. (Radostits et al., 2007).

$S$. aureus is a type of bacteria that causes severe diseases in both humans and animals. The adaptation and evolution of $S$. aureus result from mainly the presence of mobile genetic elements (MGEs) that carry virulence and resistance genes. This type of MGEs includes bacteriophage, staphylococcal cassette chromosomes (SCCs), plasmids, S. aureus pathogenicity islands (SaPIs) and transposons and they play pivotal role in horizontal gene transfer (HGT) in bacteria. They are generally present everywhere where bacteria are present and have been continuing to evolve together with bacteria for 3 to 4 billion years of life on earth. Many bacteria carry bacteriophages as either extrachromosomal genetic elements or in the form of a prophage integrated into their DNA. Bacteria cells that carry a prophage are called lysogen (Fortier and Sekulovic, 2013; Keary et al., 2014; Maslanova et al., 2013; Moon et al., 2015; Xia and Wolz, 2014).

Bacteriophage transduction is probably the most common way of HGT mechanism for $S$. aureus. (Lindsay, 2010; McCharty et al., 2012). Bacteriophages were first used in typing of clinical $S$. aureus isolates. Due to their essential roles in pathogenesis and virulence, $S$. aureus phages were
${ }^{1}$ Department of Microbiology, Faculty of Veterinary Medicine, Harran University, Şanlıurfa, Turkey.

${ }^{2}$ Department of Microbiology, Faculty of Veterinary Medicine, Dicle University, Diyarbakır, Turkey.

${ }^{3}$ Department of Physiology, Faculty of Veterinary Medicine, Dokuz Eylül University, İzmir, Turkey.

Corresponding Author: Sevil Erdenliğ Gürbilek, Department of Microbiology, Faculty of Veterinary Medicine, Harran University, Şanlıurfa, Turkey. Email: sevilerdenlig@yahoo.com

How to cite this article: Gürbilek, S.E., Arserim, N.B., Tel, O.Y., Sertkaya, Z.T. and Keskin, O. (2022). Determination of Serogroup and Lytic Activities of Bacteriophages Isolated from Phage Plaques in Staphylococcus aureus Cultures Identified from Sheep Milk with Mastitis. Indian Journal of Animal Research. DOI: 10.18805/ IJAR.BF-1443.

Submitted: 23-09-2021 Accepted: 06-12-2021 Online: 14-01-2022

examined comprehensively. Most temperate phages encode and disseminate effective staphylococcus virulence factors. It has been found out that all $S$. aureus isolates carry at least one prophage and most of them carry more than four prophages. They encode a high number of staphylococcus toxins responsible for pathogenesis. So far, more than 250 phages have been identified in staphylococci (Goerke et al., 2009; Pantucek et al., 2004; Peton and Le Loir, 2014).

A large majority of all $S$. aureus phages known so far have double-stranded DNA and long-tail temperate phages in the Siphoviridae family in the order Caudovirales. The phages enter a lytic cycle in $80-90 \%$ of the host infections 
Determination of Serogroup and Lytic Activities of Bacteriophages Isolated from Phage Plaques in Staphylococcus aureus...

with temperate phages, while they enters the lysogenic cycle in $10-20 \%$ of the bacterial infections. In the initial studies, S. aureus phages were divided into 6 serogroups. Most of the moderate phages in the Siphoviridae family are in serogroups A, B and $F$. The bacteriophages in this family are divided into 6 phage types by their lytic activity, morphology and serological characteristics. The bacteriophages in serogroup $D$ are in the Myoviridae family and those in serogroup $\mathrm{G}$ are in the Podoviridae family and non-lysogenic (Deghorain and Van Melderen, 2012; Xia and Wolz, 2014).

In this study, it was aimed to isolate bacteriophages from tiny phage plaques in $S$. aureus cultures from sheep with gangrenous mastitis. Our major aim was to isolate bacteriophages, to determine their serogroups and to reveal if they temperate or lytic phages. According to the results, all the isolated bacteriophages were temparete phages. Since these phages play important role in HGT (Fortier and Sekulovic, 2013; Maslanova et al., 2013; Moon et al. 2015; Xia and Wolz, 2014). Their isolation from directly clinical material like milk, might demonstrate different $S$. aureus strains with different virulence factors. It is important to continue to isolate $S$. aureus phages in order to increase our knowledge in virulence factors of $S$. aureus.

\section{MATERIALS AND METHODS}

\section{Bacterial strains}

S. aureus $(n=234)$ isolates were obtained from Department of Microbiology, Faculty of Veterinary Medicine, Harran University, Turkey. All the isolates were recovered from gangrenous mastitis of sheep and organisms were stored in glycerol at $-20^{\circ} \mathrm{C}$.

\section{S. aureus test phages}

Bacteriophage samples isolated from phage plaques were used in the study. For this purpose, phage samples collected with a pipette tip from a single phage plaque were diluted in PBS, propagated in their hosts and purified. They were named MK1-MK6, phage stock solutions.

\section{Positive and negative control DNA}

$S$. aureus DNAs that were lysogenized with prophages specific to serogroups (NCTC 8325, MSSA476, COL, Newman, Mu50) and DNAs from S. aureus CCM 4890 strain, which is prophage free strain, were kindly provided as positive and negative controls from Dr. Pantucek, Department of Molecular Biology and Genetics, the Czech Republic, Masaryk University.

\section{Phage DNA isolation}

Phage supernatants were concentrated with centrifugal filter tubes (Amicon ultra 15, MWCO 10K) and then genomic DNA isolation was performed using a Phage DNA isolation kit (Norgen Biotek, Canada).

\section{PCR}

PCR was performed according to the method reported by Pantucek et al. (2004) to test and control DNA samples using 6 pairs of primers to identify the phages listed in Table 1. The amplicons were run in $2 \%$ agarose gel at $120 \mathrm{~V}$ for 60 minutes and visualized under UV.

\section{RESULTS AND DISCUSSION}

According to the PCR results, MK4 $\varnothing$ and MK5 $\varnothing$ phage solutions were positive for only single serogroup, while MK2, MK3 and MK6 phage solutions were positive for 2 serogroups. On the other hand, MK1 phage sample was positive for 3 serogroups. Therefore except, MK4 $\varnothing$ and MK5 $\varnothing$ phages, they were not purified and included more than one phage. None of the phage samples were positive for Fa, $\mathrm{L}$ and $\mathrm{D}$ serogroups (Fig 1, 2, 3) and (Table 2).

MK4 $\varnothing$ solution and MK1 phages solution showed $88.9 \%$ and $27.8 \%$ lysis, respectively in $234 \mathrm{~S}$. aureus test isolates. The reason of high lytic effect of MK 4 phage solution was that it contained 3 different phage serogroup (Table 3).

Bacteriophages are the most important actors in the evolution and virulence of some important bacterial pathogens (Fortier and Sekulovic, 2013). Due to their highly

Table 1: Primers used in the study (Pantucek et al., 2004).

\begin{tabular}{|c|c|c|c|c|c|}
\hline $\begin{array}{l}\text { Phage type } \\
\text { and serogroup }\end{array}$ & Primer & Primer sequence & $\begin{array}{l}\text { PCR } \\
\text { product }\end{array}$ & $\begin{array}{l}\text { Lysogenic } S \text {. aureus } \\
\text { strains control DNAs }\end{array}$ & $\begin{array}{l}\text { Phage } \\
\text { samples }\end{array}$ \\
\hline 3 A Like & SGA1 & TATCAGGCGAGAATTAAGGG & $744 \mathrm{bp}$ & $\mathrm{COL}$ & $3 \mathrm{~A}, 3 \mathrm{C}, 6, \mathrm{~L} 54 \mathrm{~b} \varnothing$ \\
\hline A serogroup & SGA2 & CTTTGACATGACATCCGCTTGAC & & & \\
\hline 11 Like & SGB1 & ACTTATCCAGGTGGYGTTATTG & 405 bp & Newman & $11,80,85,96 \varnothing$ \\
\hline B serogroup & SGB2 & TGTATTTAATTTCGCCGTTAGTG & & & \\
\hline 77 Like & SGFa1 & TACGGGAAAATATTCGGAAG & $548 \mathrm{bp}$ & ССМ 7079 & $77,42 \mathrm{D}, 84 \varnothing$ \\
\hline F a sub serogroup & SGFa2 & ATAATCCGCACCTCATTCCT & & & \\
\hline \multirow[t]{2}{*}{$\mathrm{Fb}$ sub serogroup } & SGFb1 & AGACACATTAAGTCGCACGATAG & $147 \mathrm{bp}$ & NCTC 8325[53+] & $13 \varnothing$ \\
\hline & SGFb2 & TCTTCTCTGGCACGGTCTCTT & & & \\
\hline 187 Like & SGL1 & GCTTAAAACAGTAACGGTGACAGT & $648 \mathrm{bp}$ & $187 \varnothing$ & $187 \varnothing$ \\
\hline L serogroup & SGL2 & GCTACATCATCAAGAACACCTG & & & \\
\hline Twort Like & SGD1 & TGGGCTTCATTCTACGGTGA & $331 \mathrm{bp}$ & $812 \varnothing$ & Twort $\varnothing$ \\
\hline D serogroup & SGD2 & GTAATTTAATGAATCCACGAGAT & & & \\
\hline
\end{tabular}




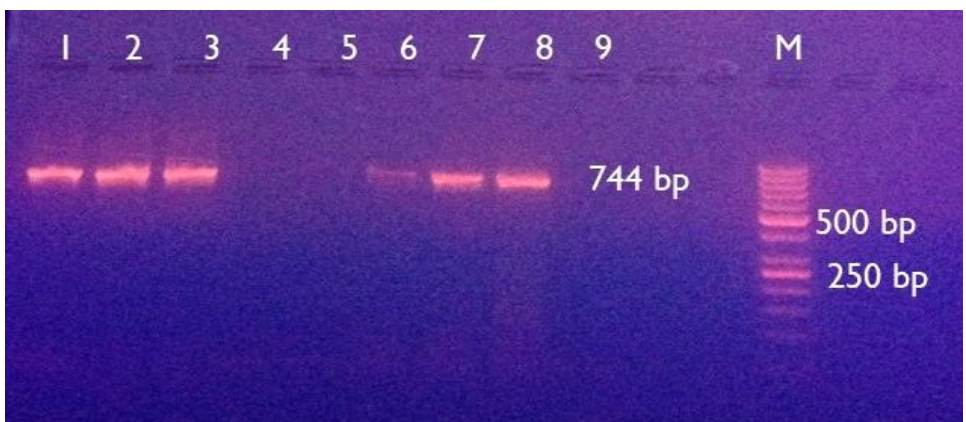

Fig 1: A phage serogroup PCR results 1. MK1; 2. MK2; 3. MK3; 4. MK4; 5. MK5; 6. MK6; 7. COL; 8. MSSA 476; 9. Negative control M. DNA marker.

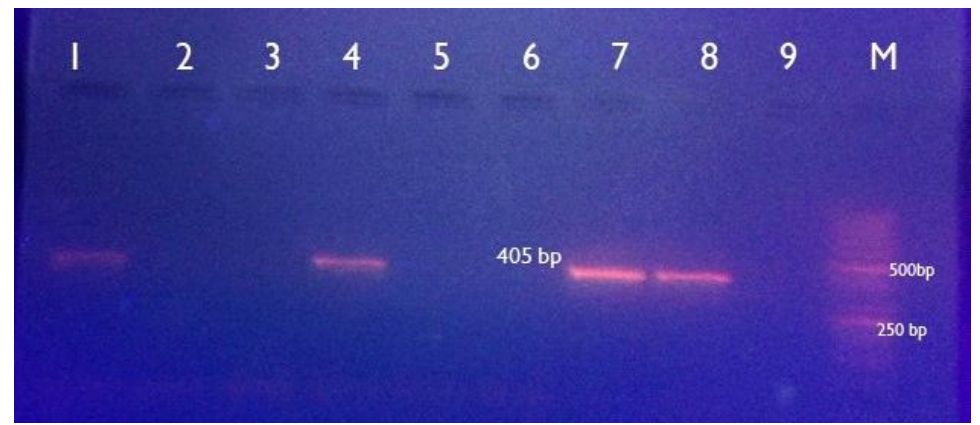

Fig 2: B phage serogroup PCR results 1. MK1; 2. MK2; 3. MK3; 4. MK4; 5. MK5; 6. MK6; 7. Newman; 8. Mu50; 9. Negative control M. DNA marker.

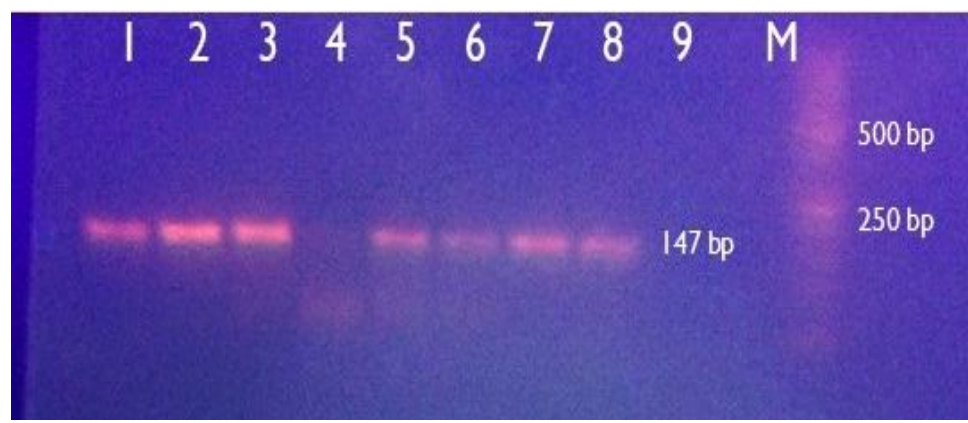

Fig 3: Fb phage serogroup PCR results 1. MK1; 2. MK2; 3. MK3; 4. MK4; 5. MK5; 6. MK6; 7. NCTC 8325; 8. MSSA476; 9. Negative control; M. DNA marker.

significant roles in pathogenesis and virulence, $S$. aureus bacteriophages are frequently studied. Bacteriophages are grouped into two main categories depending on their life cycles. There are highly consistently lytic phages (virulent) and temperate phages (Xia and Wolz, 2014).

Numerous virulence factors such as staphylococcal superantigens, proteases, leucotoxins, bacteriocins, antibiotic resistance genes are transferred by prophages settled among various human and animal $S$. aureus strains. This phenomenon called horizontal gene transfer (HGT). Moreover, it is also reported that phages play a significant role in the adaptation of $S$. aureus to very different and highly challenging conditions (Moon et al., 2015; Deghorian and Melderen, 2012; Keary et al., 2014).

S. aureus has been reported to have more than 250 phages. Large majority of $S$. aureus phages are reported to be temperate phages in the Siphoviridae family and those in serogroups A, B and F are the most common (Pantuchek et al. 2004; Xia and Wolz, 2014). In this study, in parallel to this data, only temperate phages from serogroups A, B and $F$ were identified.

In this study, serogroups were identified for the phages isolated using specific primers for 6 serogroups. Accordingly, it was found that the MK1 phage sample carried prophages from serogroups $A, B$ and $F b$; MK2, MK3 and MK6 phage samples carried prophages from serogroups $A$ and $F b$ and MK4 only carried prophages from serogroup $B$. Therefore, it was concluded that MK1, 2, 3, 5, 6 phages solutions included more than one prophage and needed to be purified.

A part of temperate phages can become lysogenic, especially in laboratory conditions, by DNA damaging, UV, mitomycin $\mathrm{C}$ and some antibiotics, mainly quinolones. It is assumed that the test phages isolated in this study transitioned from silent prophage status to lytic status for 
Determination of Serogroup and Lytic Activities of Bacteriophages Isolated from Phage Plaques in Staphylococcus aureus...

Table 2: Serogroups of the isolated phages by PCR.

\begin{tabular}{lccccc}
\hline Phage serogroup & MK1 & MK2 & MK3 & MK4 & MK6 \\
\hline A & + & + & + & - & + \\
B & + & - & - & - & - \\
Fa & - & - & - & - & - \\
Fb & + & + & - & - & - \\
L & - & - & - & - \\
D & - & - & - & - \\
\hline
\end{tabular}

Table 3: Lysis results of isolated phages.

\begin{tabular}{lccc}
\hline Phage & $\begin{array}{c}\text { Number of } \\
\text { lysed isolates }\end{array}$ & $\begin{array}{c}\text { Number of } \\
\text { non-lysed isolates }\end{array}$ & Total \\
\hline MK1 & 65 & 169 & 234 \\
MK2 & - & 234 & 234 \\
MK3 & - & 234 & 234 \\
MK4 & 208 & 26 & 234 \\
MK5 & - & 234 & 234 \\
MK6 & - & 234 & 234 \\
\hline
\end{tabular}

these reasons and they most probably came from the host strain. These findings are also in compliance with the previous workers (Deghorian and Melderen, 2012; Lindsay, 2010).

In this study, 234 S. aureus isolates were used to evaluate the lytic effect of phages. Most was caused by phages from B serogroup. Researchers (Xia and Wolz, 2014) reported that serogroup $B$ phages were the most studied phages and this group of phages has very high transduction efficiency. For this reason, this phage is believed to be capable of a very high lytic effect. That MK1 and MK4 phage solution include serogroup B phages strengthens this assumption.

In our next study will be to determine lysogenic level of our $S$. aureus isolates. Temperate phages in clinical $S$. aureus isolates can be identified with multiplex PCR. Goerke et al. (2009) determined one or more prophages in most of the tested isolates in their study on the diversity of prophages on dominant S. aureus lineages. Maslanova et al. (2013) reported that multiple lysogens were observed in most $S$. aureus strains in the natural environment. To detect prophages in our local $S$. aureus strains will increase our knowledge virulence mechanisms of $S$. aureus.

\section{CONCLUSION}

In conclusion, it was demonstrated that bacteriophages isolated through purification in the study were temperate phages that played a significant role in horizontal gene transfer. Continuing studies on the isolation of temperate phages that play such an important role in horizontal gene transfer are of utmost importance in demonstrating some phages yet to be discovered. It is planned to identify the lysogenic e $S$. aureus test strains and then study the existence of significant $S$. aureus virulence factors in them for the next step of the study.

\section{REFERENCES}

Deghorian, M. and Van Melderen, L. (2012). The Staphylococci phages family: An overview. Viruses. 4: 3316-3335.

Fortier, L.C. and Sekulovic, O. (2013). Importance of prophages to evolution and virulence of bacterial pathogens. Virulence. 4(5): 354-365.

Goerke, C., Pantucek, R., Holtfreter, S., Schulte, B., Zink, M., Grumann, D., Bröker, B.M., Doskar, J., Wolz, C. (2009). Diversity of prophages in dominant Staphylococcus aureus clonal lineages. Journal of Bacteriology. 191(11): 3462-3468.

Keary, R., McAuliffe, O., Ross, R.P., Hill, C., O'Mahony, J., Coffey, A. (2014). Genome analysis of the staphylococcal temperate phage DW2 and functional studies on the endolysin and tail hydrolase. Bacteriophage. 4:1, e28451. DOI: 10.4161/ bact.28451.

Lindsay, J.A. (2010). Genomic variation and evolution of Staphylococcus aureus. International Journal of Medical Microbiology. 300: 98-103.

Maslanova, I., Doskar, J., Varga, M., Kuntova, L., Muzik, J., Maluskova, D., Ruzickova, V., Pantucek, R. (2013). Bacteriophages of Staphylococcus aureus efficiently package various bacterial genes and mobile genetic elements including $\mathrm{SCCmec}$ with different frequencies. Environmental Microbiology Reports. 5(1): 66-73.

McCarthy, A.J., Witney, A.A., Lindsay, J.A. (2012). Staphylococcus aureus temperate bacteriophage: carriage and horizontal gene transfer is lineage associated. Frontiers in Cellular and Infection Microbiology. 2: 1-10.

Moon, B.Y., Park, J.Y., Hwang, S.Y., Robinson, D.A., Thomas, J.C., Fitzgerald, J.R., Park, Y.H., Seo, K.S. (2015). Phagemediated horizontal transfer of a Staphylococcus aureus virulence-associated genomic island. Scientific Reports. 5: 9784. https://doi.org/10.1038/srep09784.

Pantucek, R., Doskar, J., Ruzickova, V., Kasparek, P., Oracova, E., Kvardova, V., Rosypal, S. (2004). Identification of bacteriophage types and their carriage in Staphylococcus aureus. Archives of Virology. 149: 1689-1703.

Peton, V. and Le Loir, Y. (2014). Staphylococcus aureus in veterinary medicine. Infection, Genetics and Evolution. 21: 602-615.

Radostits, O.M., Gay, C.C., Hinchcliff, K.W. and Constable, P.D. (2007). Veterinary Medicine: A Text Book of the Disease of Cattle, Horses, Sheep, Pigs and Goats. $10^{\text {th }}$ ed. Elsevier Ltd, London.

Xia, G. and Wolz, C. (2014). Phages of Staphylococcus aureus and their impact on host evolution. Infection, Genetics and Evolution. 21: 593-601. 